\title{
Stability of individual loudness functions obtained by magnitude estimation and production
}

\author{
RHONA P. HELLMAN \\ Department of Communication Disorders, Boston University, Boston, Massachusetts 02215
}

\begin{abstract}
A correlational analysis of individual magnitude estimation and production exponents at the same frequency was performed, as well as an analysis of individual exponents produced in different sessions by the same procedure across frequency $(250,1,000$, and $3,000 \mathrm{~Hz})$. Taken together, results show, first, that individual exponent differences do not decrease by counterbalancing magnitude estimation with magnitude production, and, second, that individual exponent differences remain stable over time despite changes in stimulus frequency. Further results disclose that although individual magnitude estimation and production exponents do not necessarily obey the .6 power law, it is possible to predict the slope (exponent) of an equal-sensation function averaged for a group of listeners from individual magnitude estimation and production data. Assuming that individual listeners with sensorineural hearing loss also produce stable and reliable magnitude functions, it is also shown that the slope of the loudness-recruitment function measured by magnitude estimation and production can be predicted for individuals with bilateral losses of long duration. Thus, results obtained in normal and in pathological ears suggest that individual listeners can produce loudness judgments that reveal, albeit indirectly, the input-output characteristic of the auditory system.
\end{abstract}

The intersubject variability of individual magnitude estimation and production exponents is puzzling in view of the persistence of power-function behavior for both individual and group data. For loudness and brightness, the variation in individual powerfunction exponents measured by magnitude estimation or by a combined estimation-production procedure is greater than 2:1 (Marks \& J. C. Stevens, 1966; J. C. Stevens \& Guirao, 1964). The evidence now indicates that interindividual exponent differences of this magnitude are repeatable and stable over time (e.g., Barbenza, Bryan, \& Tempest, 1970; Logue, 1976; McGill, 1974; Schneider \& Lane, 1963; Wanschura \& Dawson, 1974). Wanschura and Dawson (1974) also found that balancing for regression in a cross-modality task does not remove individual exponent differences that remain consistent and persist over sessions. Although the explanation of individual exponent differences is unclear, the implications of these findings are extremely important.

I would like to thank Nelson Kiang of the Eaton-Peabody Laboratory and Rhoda Morrison of the Massachusetts Eye and Ear Infirmary for referral of two of the listeners with sensorineural loss. The third listener was kindly referred to me by $\mathbf{R}$. Barlow of the Institute for Sensory Research, Syracuse University. Portions of this paper were presented in June 1979 at the 97 th meeting of the Acoustical Society of America. Supported, in part, by a grant from NASA-Langley Research Center.
Despite the variability of individual exponents obtained for loudness, the average value measured at $1,000 \mathrm{~Hz}$ for a group of 9 to 11 listeners is typically .60 re sound pressure (S. S. Stevens, 1955, 1957). This value has become the accepted international standard (International Organization for Standardization, 1959). Whereas the loudness exponent measured for an individual may differ from the typical value, the analysis to be presented in this article indicates that the slope (exponent) of an equal-sensation function averaged for a group of listeners can be predicted from individual magnitude estimation and production data. Thus, although individual magnitude estimation and production exponents do not necessarily obey the .6 power law, the stability of obtained values for individuals preserves the slope of the matching function measured for the group and hence suggests that for normal-hearing listeners, the intersubject variability at the output of the sensory transducer is relatively small.

Assuming further that individual listeners with cochlear pathology also produce stable and reliable magnitude functions, it is also shown that, using a battery of procedures as advocated by S. S. Stevens $(1959,1971,1975)$, the slopes of three different psychophysical functions are interrelated so that the slope of any one function can be predicted from the relative slopes measured for the other two. Moreover, it appears possible to predict the slope of the loudness- 
Table 1

Correlation Coefficients (Magnitude Estimation vs. Magnitude Production)

\begin{tabular}{lrrrrrr}
\hline \multicolumn{1}{c}{ Source } & $\mathrm{F}$ & $\mathrm{T}_{\mathbf{x y}}$ & $\mathrm{CD}$ & $\mathrm{N}$ & $\mathrm{t}$ & $\mathrm{p}^{*}$ \\
\hline (Hellman \& Zwislocki, 1968) & 250 & +.520 & 27.0 & 9 & 1.60 & .10 \\
(Hellman, 1976) & 3000 & +.385 & 14.8 & 8 & 1.02 & .20 \\
Group 1 (Hellman, 1976) & 1000 & +.566 & 32.0 & 10 & 1.94 & .10 \\
Group 2 (Hellman \& Zwislocki, 1963) & 1000 & +.380 & 14.0 & 9 & 1.10 & .20 \\
Combined Groups 1 and 2 & 1000 & +.440 & 19.0 & 19 & 2.01 & .05 \\
\hline
\end{tabular}

Note $-F=$ frequency (in Hertz); $C D=$ coefficient of determination (in percent). $\quad{ }^{*} p>$ value shown.

Table 2

Correlational Analysis of Individual Exponents Obtained by Magnitude Estimation and Magnitude Production at Different Frequencies

\begin{tabular}{|c|c|c|c|c|c|c|c|c|c|}
\hline & \multicolumn{3}{|c|}{ ME vs. ME } & \multicolumn{3}{|c|}{ MP vs. MP } & \multicolumn{3}{|c|}{ G Mns ME vs. MP } \\
\hline & $r_{x y}$ & $\mathrm{CD}$ & $\mathrm{t}$ & $I_{x y}$ & $\mathrm{CD}$ & $t$ & $r_{x y}$ & $\mathrm{CD}$ & $t$ \\
\hline $\begin{array}{l}1 \mathrm{kHz} \text { vs. } 250 \mathrm{~Hz} \\
1 \mathrm{kHz} \text { vs. } 3 \mathrm{kHz}\end{array}$ & $\begin{array}{l}+.65 \\
+.95\end{array}$ & $\begin{array}{l}42 \\
90\end{array}$ & $\begin{array}{l}1.9^{*} \\
6.7 \dagger\end{array}$ & $\begin{array}{l}+.92 \\
+.88\end{array}$ & $\begin{array}{l}85 \\
77\end{array}$ & $\begin{array}{l}5.3 \dagger \\
4.1 \dagger\end{array}$ & $\begin{array}{r}+.910 \\
+.985\end{array}$ & $\begin{array}{l}83 \\
97\end{array}$ & $\begin{array}{r}4.9 \dagger \\
12.7 \dagger\end{array}$ \\
\hline
\end{tabular}

Note $-N=7 . C D=$ coefficient of determination (in percent). $\quad * p>.10 . \quad t_{p}<.01$.

recruitment function on the basis of direct numerical judgments indicating that magnitude estimation and production can be used to measure the input-output characteristic of the pathological ear.

This article is divided into two sections. The first section involves a reanalysis of already published loudness data obtained in normal ears (Hellman, 1974, 1976; Hellman \& Zwislocki, 1963, 1968). The second section presents new data determined by three listeners with known bilateral sensorineural hearing loss.

\section{NORMAL HEARING}

A correlational analysis of individual magnitude estimation and production exponents at the same frequency has been performed, as well as an analysis of individual exponents produced in different sessions by the same procedure across frequency $(250$, 1,000 , and $3,000 \mathrm{~Hz}$ ).

Product-moment correlation coefficients calculated between individual magnitude estimation and production exponents measured in three different experiments (Hellman, 1976; Hellman \& Zwislocki, 1963, 1968) are shown in Table 1. The individual exponents at $250 \mathrm{~Hz}$ were calculated above $40 \mathrm{~dB} \mathrm{SL}$, where the $250-\mathrm{Hz}$ loudness function is approximately as steep as the function at $1,000 \mathrm{~Hz}$. Table 1 indicates that the obtained correlations are all positive (vary from +.38 to +.566 ) but not statistically significant ( $>.05$ ). Increasing the group size to 19 by combining $1,000-\mathrm{Hz}$ data from two different experimental series does not change this result. Individual differences in power-function exponents do not appear to decrease when magnitude estimation is counterbalanced by magnitude production, as S. S. Stevens expected $(1971,1975)$. Very similar results and conclusions were reported earlier (Lilienthal \& Dawson, 1976; Wanschura \& Dawson, 1974) on the basis of cross-modality matching between loudness and apparent time duration.

Furthermore, the individual differences in loudness exponents appear to be a stable and persistent effect. Product-moment correlation coefficients obtained between individual exponents produced in different sessions by the same procedure are all positive and vary from +.65 to +.985 despite a change in stimulus frequency. These results are indicated in Table 2. The intersession time interval between the measurements at 1,000 and $3,000 \mathrm{~Hz}$ was 4 to 6 weeks and, between the 1,000 - and $250-\mathrm{Hz}$ measurements, it was close to 6 months. According to Table 2, with the exception of the correlation computed between individual magnitude estimation exponents at 1,000 and $250 \mathrm{~Hz}$, the remaining correlations are all statistically significant $(p<.01)$.

The last three columns in Table 2 are of particular importance because these interfrequency correlations are based on the combined results of magnitude estimation and production for each listener at each frequency. Hence, each value of $r_{x y}$ is based on the results of four separate psychophysical functions for each listener. Thus, 28 functions at 1,000 and $250 \mathrm{~Hz}$ were analyzed to obtain the correlation coefficient of +.91 , and 28 functions at 1,000 and $3,000 \mathrm{~Hz}$ were analyzed to obtain the correlation coefficient of +.985 . Such high correlations indicate that more than $80 \%$ of the variance of the individual exponents can be ascribed to stable, enduring characteristics of the individual.

The correlation coefficients shown in Table 2 are larger than those reported previously for magnitude estimation-production procedures (Logue, 1976; J. C. Stevens \& Guirao, 1964), but they are in accord 
with the correlation of .95 obtained for 15 observers by Barbenza et al. (1970). Moreover, they agree with the high intraindividual consistency measured over time by Schneider and Lane (1963) for one listener and with the more extensive cross-modality measurements between loudness and brightness reported recently by Walsh and Browman (1978). Taken together, Tables 1 and 2 show, first, that individual exponent differences do not decrease by counterbalancing magnitude estimation with magnitude production and, second, that individual exponent differences remain stable over time despite changes in stimulus frequency.

The finding that individual loudness exponents persist over time extends the work of Wanschura and Dawson (1974) and of Logue (1976) to an intersession interval of 6 months. The results for loudness appear to differ from the data by Teghtsoonian and Teghtsoonian (1971) based on magnitude estimations of line length and area. However, Engeland and Dawson (1974) failed to confirm those results for apparent area. Hence, the area data by Teghtsoonian and Teghtsoonian (1971) are inconclusive. No additional data are available for apparent length. It seems unlikely that line length and area judgments behave differently from other sensory modalities, particularly loudness, but this issue remains to be resolved.

Figure 1 shows the scatter of individual exponents used to calculate the correlation coefficients indicated in Table 2, column 7. The exponents were calculated by determining above $30 \mathrm{~dB}$ SL (40 dB SL at $250 \mathrm{~Hz}$ ) the geometric mean of the individual exponents obtained at each frequency by both magnitude estimation and magnitude production. The unfilled circles show how the exponents at 1,000 and $3,000 \mathrm{~Hz}$ covary; the filled circles show how those measured at 250 and $1,000 \mathrm{~Hz}$ covary. Since each point indicates the result of four psychophysical functions for each listener, the 14 points represent an analysis of 56 individual magnitude functions. The scatter of individual exponents ranges from .38 to 1.0 re sound pressure, but there is a clustering of individual exponent values between .50 and .63 . Seven of the 14 individual exponent pairs at the three stimulus frequencies lie within this range. The median of this group corresponds to the point .57 and .60 . Furthermore, the approximate geometric average of the extreme values is also close to .60 , the exponent established for loudness as an international standard (International Organization for Standardization, 1959).

Although the counterbalanced procedures of magnitude estimation and production do not decrease the observed interindividual differences in exponents, the combined procedures of magnitude estimation and production yield an average exponent value for each person that bears a systematic relation to a similarly obtained value at a different frequency.

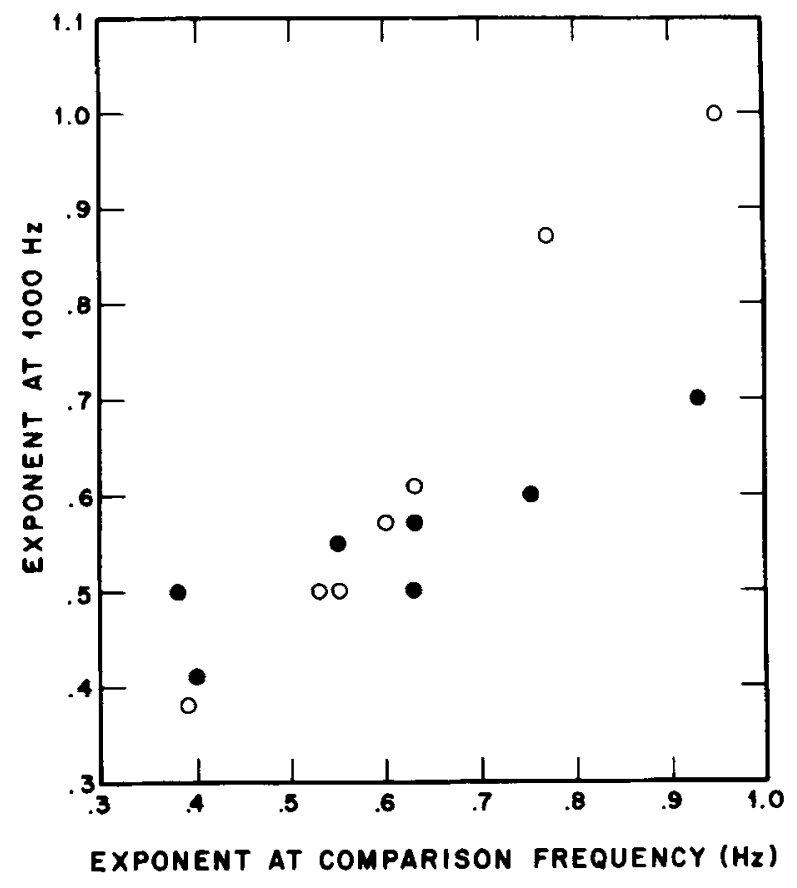

Figure 1. Covariation of individual exponents at 1,000 and $250 \mathrm{~Hz}$ and at 1,000 and $3,000 \mathrm{~Hz}$. Each point indicates the result of four psychophysical functions for each observer. Filled circles represent exponents measured at 1,000 and $250 \mathrm{~Hz}$, and unfilled circles represent those measured at 1,000 and $3,000 \mathrm{~Hz}$.

Table 3 shows an analysis of 1,000 and $3,000-\mathrm{Hz}$ data from Figure 1 as well as individual measurements for two listeners obtained at $250 \mathrm{~Hz}$ in quiet and in the presence of an adjacent high-frequency band-pass noise (Hellman, 1974). The standard deviation of .22 at $1,000 \mathrm{~Hz}$ and .18 at $3,000 \mathrm{~Hz}$ is comparable to that obtained by J. C. Stevens and Guirao (1964). A slightly smaller value of .15, about the same as that reported by Logue (1976), is obtained for the larger group of 19 listeners. However, despite the variation in individual exponents, the exponent ratio produced at 1,000 and $3,000 \mathrm{~Hz}$ for each listener is nearly 1.0. An exponent of 1.0 is the obtained average slope determined indirectly by intramodality matching between 1,000 and $3,000 \mathrm{~Hz}$ for a different group of listeners (Hellman, 1976). A similar pattern for individuals is revealed at 1,000 and $250 \mathrm{~Hz}$. Clearly, computing the relative exponent for each listener reduces dramatically the apparent interindividual variation (standard deviation $=.08$ ) in exponents so that the slope of the predicted matching function by the individual closely approximates the measured behavior of the group. This finding is in accord with the tentative conclusion arrived at for brightness by Marks and J. C. Stevens (1966).

The two listeners for whom exponents at $250 \mathrm{~Hz}$ are indicated in Table 3 are equally instructive, for 
Table 3

Exponent of Equal-Sensation Function Obtained from Combined Individual Magnitude Estimation and Magnitude Production Data

\begin{tabular}{|c|c|c|c|c|c|}
\hline & \multirow[b]{2}{*}{$\theta$ at $1 \mathrm{kHz} *$} & \multirow[b]{2}{*}{$\theta$ at $3 \mathrm{kHz}$} & \multirow{2}{*}{$\begin{array}{c}\theta 1 \mathrm{kHz} / \theta 3 \mathrm{kHz} \\
\text { (Predicted) }\end{array}$} & \multicolumn{2}{|c|}{$\theta 250 \mathrm{~Hz}$ in Noise $/ \theta 250 \mathrm{~Hz}$ in Quiet } \\
\hline & & & & Predicted & Measured $\dagger$ \\
\hline & .61 & .63 & .97 & $.84(.36 / .43)$ & .90 \\
\hline & .50 & .55 & .91 & $.93(.57 / .61)$ & 1.00 \\
\hline & .87 & .77 & 1.13 & & \\
\hline & .50 & .53 & .94 & & \\
\hline & 1.00 & .95 & 1.05 & & \\
\hline & .38 & .39 & .97 & & \\
\hline & .57 & .60 & .95 & & \\
\hline$\overline{\mathrm{X}}_{\theta}$ & .63 & .63 & 1.00 & & \\
\hline SD & .22 & .18 & .08 & & \\
\hline
\end{tabular}

$* \bar{X}_{\theta} 1 \mathrm{kHz}(N=19)=.60 ; S D=.15 . \quad$ tHellman $(1974)$.

Table 4

Exponent of Equal-Sensation Function Obtained from Individual Magnitude Estimation and Magnitude Production Data

\begin{tabular}{|c|c|c|c|c|c|c|}
\hline & \multicolumn{3}{|c|}{ Magnitude Estimation } & \multicolumn{3}{|c|}{ Magnitude Production } \\
\hline & $\theta$ at $1 \mathrm{kHz}$ & $\theta$ at $3 \mathrm{kHz}$ & $\theta 1 \mathrm{kHz} / \theta 3 \mathrm{kHz}^{*}$ & $\theta$ at $1 \mathrm{kHz}$ & $\theta$ at $3 \mathrm{kHz}$ & $\theta 1 \mathrm{kHz} / \theta 3 \mathrm{kHz} *$ \\
\hline & $\begin{array}{r}.43 \\
.40 \\
.63 \\
.50 \\
1.00 \\
.24 \\
.38\end{array}$ & $\begin{array}{r}.60 \\
.46 \\
.60 \\
.46 \\
1.20 \\
.28 \\
.54\end{array}$ & $\begin{array}{r}.72 \\
.87 \\
1.05 \\
1.09 \\
.83 \\
.86 \\
.70\end{array}$ & $\begin{array}{r}.86 \\
.63 \\
1.20 \\
.50 \\
1.00 \\
.60 \\
.86\end{array}$ & $\begin{array}{r}.66 \\
.66 \\
1.00 \\
.60 \\
.75 \\
.54 \\
.66\end{array}$ & $\begin{array}{r}1.30 \\
.95 \\
1.20 \\
.83 \\
1.33 \\
1.11 \\
1.30\end{array}$ \\
\hline $\begin{array}{l}\bar{X}_{\theta} \\
\text { SD } \\
\end{array}$ & $\begin{array}{l}.51 \\
.25 \\
\end{array}$ & $\begin{array}{l}.59 \\
.29 \\
\end{array}$ & $\begin{array}{l}.87 \\
.15 \\
\end{array}$ & $\begin{array}{l}.81 \\
.25 \\
\end{array}$ & $\begin{array}{l}.70 \\
.15\end{array}$ & $\begin{array}{r}1.15 \\
.19\end{array}$ \\
\hline
\end{tabular}

Note-The ratio of the values in the first two columns and in Columns 4 and 5 predicts the matching exponents listed in Columns 3 and 6 , respectively. *Predicted.

these listeners participated in both the magnitude estimation and production experiments as well as in the intramodality matching task. In this example, the tone-to-noise ratio was held constant at either +10 or $0 \mathrm{~dB}$. These tone-to-noise ratios were shown to reduce the slope of the matching function for the group from 1.0 to about .95 (Hellman, 1974). According to Table 3, the agreement between the predicted and measured exponents for each listener is very close. The individual values also agree quite closely with the group value, meaning that individual magnitude estimation and production data can convey information about the relation of the spread of excitation to loudness growth.

Interestingly, the ability of individual listeners to predict group behavior is poorer when either magnitude estimation or magnitude production is studied alone. ' Table 4 shows the individual exponents produced by the same listeners at 1,000 and $3,000 \mathrm{~Hz}$ by both magnitude estimation and magnitude production. According to Table 4, the relative group exponents averaged for either magnitude estimation or magnitude production are in reasonably good agreement with the group value determined by equalsensation matching but not the individual values.
Magnitude estimation tends to underestimate the matching exponent measured for the group, whereas magnitude production tends to overestimate it (e.g., S. S. Stevens, 1969; S. S. Stevens \& Greenbaum, 1966). By combining the individual results of magnitude estimation with those of magnitude production, the agreement between the equal-sensation exponent predicted for individuals and the measured group exponent determined by intramodality matching is substantially improved.

Taken together, Tables 3 and 4 appear to suggest that, when individual magnitude estimation and production functions are combined, transitivity can be achieved for normal-hearing listeners. Moreover, individual magnitude functions can be used to describe group behavior. On the basis of these findings, it is hard to escape the conclusion that individual numerical magnitude functions can reveal, albeit indirectly, the input-output characteristic of the auditory system. However, caution is necessary, for no single procedure by itself is sufficient. Several different procedures for each listener are required to obtain a meaningful and valid result. S. S. Stevens $(1959,1969,1971,1975)$ argued on numerous occasions against reliance on any one procedure and 
consistently advocated using a battery of procedures for both individuals and groups. A powerful test of this approach is to demonstrate its applicability to hearing pathology. In the next section, it is shown that the slope of the loudness-recruitment function measured in cochlear pathology by magnitude estimation and production can be predicted for individual listeners.

\section{HEARING LOSS}

\section{Method}

Subjects. Three observers with bilateral symmetrical highfrequency hearing losses participated in the experiments. Two observers were diagnosed by the Massachusetts Eye and Ear Infirmary, and the third, by the Boston Hard of Hearing Guild. The hearing loss of one observer was noise induced, one was of unknown, probably genetic, origin, and the origin of the third was congenital. This last observer had the most profound hearing loss $(82 \mathrm{~dB}$ at $1,000 \mathrm{~Hz})$. The hearing of all three observers was reevaluated in greater detail for the laboratory measurements.

Procedures. In addition to the initial evaluations, each observer participated, over a period of about 6 weeks, in a series of psychophysical experiments that involved judgments of loudness in the normal and abnormal frequency ranges. Only those data obtained in the abnormal range are described in this article. Since the measured hearing losses were bilateral, following S. S. Stevens' (1959) suggestion, the presence of loudness recruitment was individually determined by including data based on another, presumably normally functioning, continuum. Line length was chosen for this purpose because of the relative simplicity of stimulus control, and it is relatively easy for observers to juage (S. S. Stevens \& Guirao, 1963).

The observers, seated in a soundproofed booth, judged subjective line lengt $h$ and loudness by one of three psychophysical methods: (1) absolute magnitude estimation (AME), (2) absolute magnitude production (AMP), and (3) cross-modality matching. The loudness adjusinents for both magnitude production and cross-modality matching were made with a sone potentiometer that covered a 60-dB range. Listening was monaural through a TDH-39 earphone mounted in an MX-41/AR socket. The earphone was calibrated on a standard $6-\mathrm{cm}^{3}$ coupler and showed an essentially flat response $( \pm 1.5 \mathrm{~dB})$ from 100 to $3,000 \mathrm{~Hz}$.

The magnitude estimation procedure was the same for both subjective line length and loudness. in accordance with earlier work by Hellman and Zwislocki (1961, 1963, 1968), no standard was given and the individual raw data were averaged without normalization. Each observer was asked simply to match an appropriate number to the loudness (or length) of the tone (or line) regardless of the number assigned to the previous stimulus. Magnitude estimation of line length preceded magnitude estimation of loudness. Three series of judgments were obtained but only the last two were used to compute geometric means. The stimuli were presented in a quasirandom order that differed from listener to listener and, within a session, from series to series.

After the completion of magnitude estimation of length and of loudness, the observer was asked to judge the loudness of the tone by magnitude production without a standard. The range of numbers used in magnitude production was derived from the individual range determined by magnitude estimation. As in loudness matching between two sounds, the observers were asked to match loudness and numbers by bracketing, that is, to adjust the loudness of the variable stimulus to loudnesses both above and below the subjective magnitude of the assigned number, and to determine the approximate equal-sensation point within these limits. Two adjustments to each number were obtained for each observer, who was allowed either to listen to the tone or to adjust its intensity, but not both at the same time (Hellman \& Zwislocki, 1964). Decibel averages of the two adjustments to each number were determined individually and plotted separately, without normalization, for each observer.

Cross-modality matches between loudness and line length were obtained in the same setup and manner as for magnitude production. However, rather than match loudness to numbers assigned by the experimenter, the observer was asked to adjust the loudness of the tone until it appeared subjectively equal to the length of an assigned line. Two adjustments to each length were obtained for each observer, and the decibel average of both judgments was determined individually. The line length stimuli were the same as those used for magnitude estimation of length.

Stimuli. The stimuli consisted of pure tones and lines at seven lengths that ranged from .5 to $32 \mathrm{~cm}$. Lines drawn in black ink on large pieces of oak tag were viewed by each observer from inside the soundproofed room, a distance of about $170 \mathrm{~cm}$. The tones could be turned on and off at will by means of a manual switch. Loudness functions were obtained individually at a frequency in the region of maximum hearing loss. For Observer 1 , the test stimulus was at $2,000 \mathrm{~Hz}$; for Observer 2, it was at $4,000 \mathrm{~Hz}$; and for Observer 3, it was at $1,000 \mathrm{~Hz}$. The stimulus range was determined by each observer's individual sensitivity to loud sounds. The range for Observer 1 was from 4 to $40 \mathrm{~dB} \mathrm{SL}$; for Observer 2, it was from 4 to $35 \mathrm{~dB} \mathrm{SL}$; and for Observer 3, it was from 4 to $30 \mathrm{~dB} \mathrm{SL}$.

The following hypotheses were tested: (1) Transitivity can be achieved for individual observers with bilateral sensorineural hearing loss. (2) Observers with sensorineural hearing loss can use the numerical procedures of magnitude estimation and production in a meaningful and valid way to represent the input-output function of the sensory transducer.

\section{Results and Discussion}

Figure 2 shows the individual results obtained by magnitude estimation of length. Each point indicates the geometric mean of the final two judgments produced by each observer. The individual data for all three observers are well approximated by a power function of stimulus length. The indicated exponents were determined by a least squares fit. Consistent with previous results for brightness and loudness (Marks \& J. C. Stevens, 1966; J. C. Stevens \& Guirao, 1964), the variation in individual exponents is somewhat greater than $2: 1$, but the median value of 1.07 closely approximates an exponent of 1.0 typically measured for subjective line length (S. S. Stevens \& Guirao, 1963).

Individual loudness functions determined by magnitude estimation and by magnitude production are shown in Figure 3, together with cross-modality matches obtained between loudness and length. Panel $\mathbf{A}$ indicates the results measured for Observer 1, and Panel B indicates those measured for Observer 2. The threshold of audibility measured at the stimulus frequency for these two observers was about $66 \mathrm{~dB}$ SPL. Results similar to those in Figure 3 are shown in Figure 4 for Observer 3, who had a measured threshold at $1,000 \mathrm{~Hz}$ of $82 \mathrm{~dB}$ SPL. The indicated exponents were determined by a least squares fit to the data.

In both Figures 3 and 4, the filled circles represent the results of magnitude estimation, the crosses those of magnitude production, and the unfilled circles indicate the cross-modality matches. The three mag- 


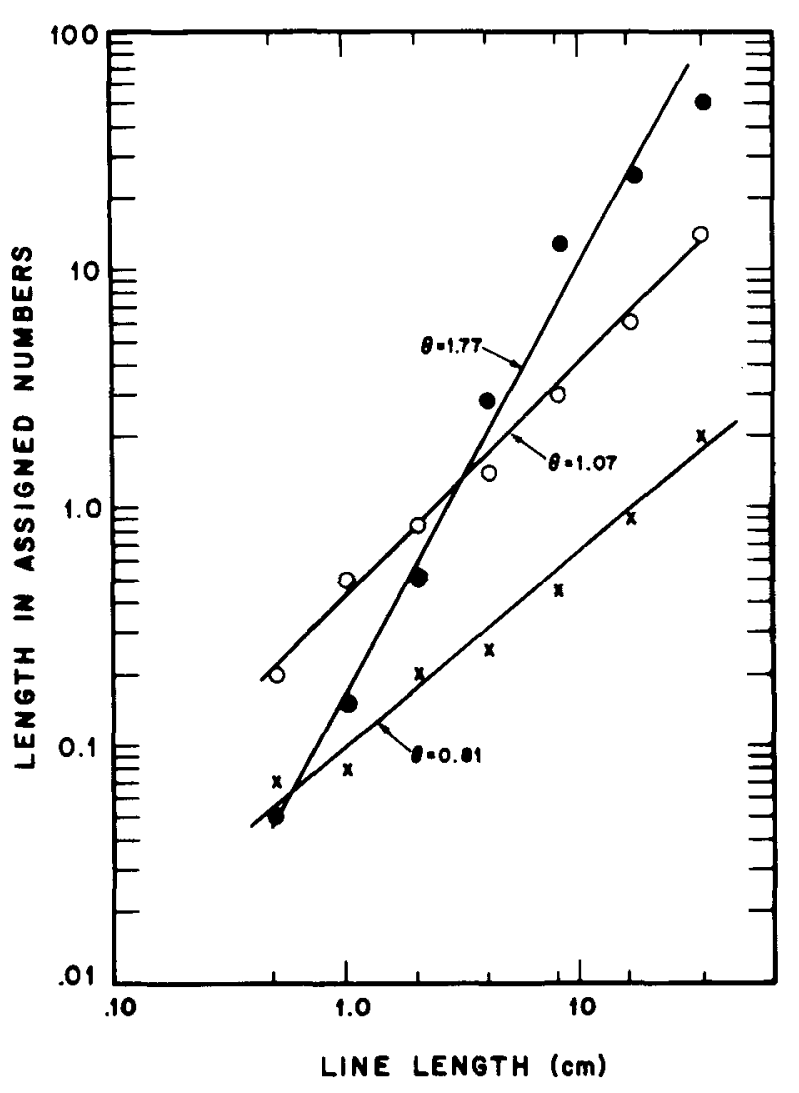

Figure 2. Individual results obtained by magnitude estimation of length for three observers with a bilateral sensorineural hearing loss. Crosses represent geometric means of Observer 1 , unfilled circles represent geometric means of Observer 2 , and filled circles represent those of Observer 3.

nitude functions shown for each hearing-impaired listener are based on measurements obtained along the steep portion of the loudness-recruitment function. The ranges of sound pressure levels covered by the three functions are comparable for each listener. ${ }^{2}$ All the data, except the cross-modality matches, are plotted as a function of absolute sound pressure level. Relative to the loudness data, the cross-modality matches are shifted by $20 \mathrm{~dB}$ to higher SPLs, so that the equal-sensation function can be clearly distinguished from the functions produced by magnitude estimation and production. Moreover, although length is plotted along the ordinate and SPL along the abscissa, during the experiment, loudness, not length, was the adjusted variable. Hence, the exponent of each equal-sensation function represents the relation between loudness and length. This value is actually the reciprocal of the exponent determined by the plot of the data.

Several features of the results in Figures 3 and 4 may be noted. First, over the indicated ranges of sound pressure levels, the individual data can be adequately described by a simple power function in the form $\psi=K \phi^{\theta}$. Second, as typically found (S. S. Stevens \& Greenbaum, 1966), magnitude production results in a steeper function than magnitude estimation. Third, since both number and loudness were matched to the same length continuum, it is possible to predict the slope (exponent) relating loudness to number. This predicted slope can then be compared with the measured slope of the loudness function. The results show that for each observer, the relative slope measured for length and by cross-modality matching closely predicts the measured slope determined for loudness by the combined procedures of magnitude estimation and production. This finding is indicated in Table 5 . The close agreement between the predicted and measured slopes (columns 3 and 4) does not obtain for either magnitude estimation or production of loudness alone. Finally, in accord with the outcome of masked loudness measurements in normal ears (Chocholle \& Greenbaum, 1966; Hellman \& Zwislocki, 1964; Lochner \& Burger, 1961; Scharf, 1964; S. S. Stevens \& Guirao, 1967) and with group data determined by ears with sensorineural hearing loss (Miskolczy-Fodor, 1960), the results show that the slope of the loudness-recruitment function depends on the threshold of audibility; that is, the higher the threshold, the steeper the function. Both observers with a threshold at $66 \mathrm{~dB}$ SPL produce a function with a slope close to 1.0. By comparison, the observer with a threshold at $82 \mathrm{~dB}$ SPL produces a function with a slope of about 2.4 .

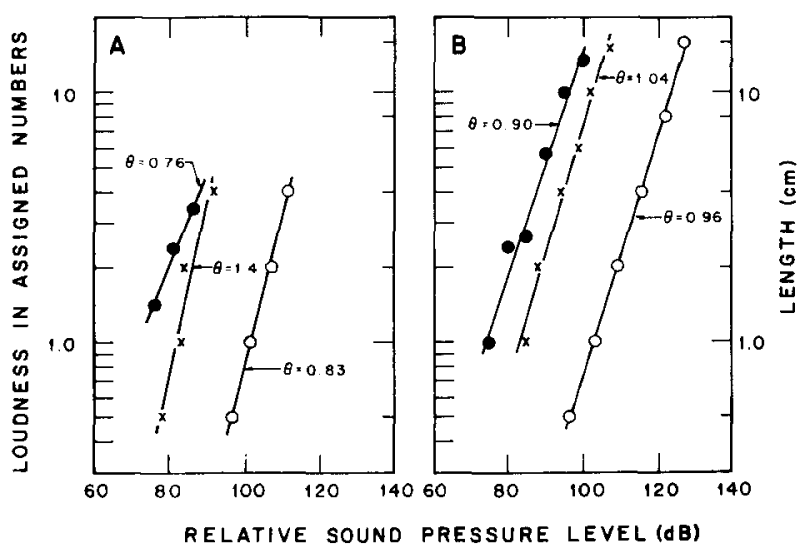

Figure 3. Individual loudness functions determined by magnitude estimation and by magnitude production, together with crossmodality matches obtained between loudness and length. Panel $A$ indicates the results measured for Observer 1 , and Panel $B$ indicates those measured for Observer 2. The threshold of audibility measured at the stimulus frequency for these two observers was about $66 \mathrm{~dB}$ SPL. Filled circles represent the results of magnitude estimation; crosses, those of magnitude production; and unfilled circles indicate the cross-modality matches. 


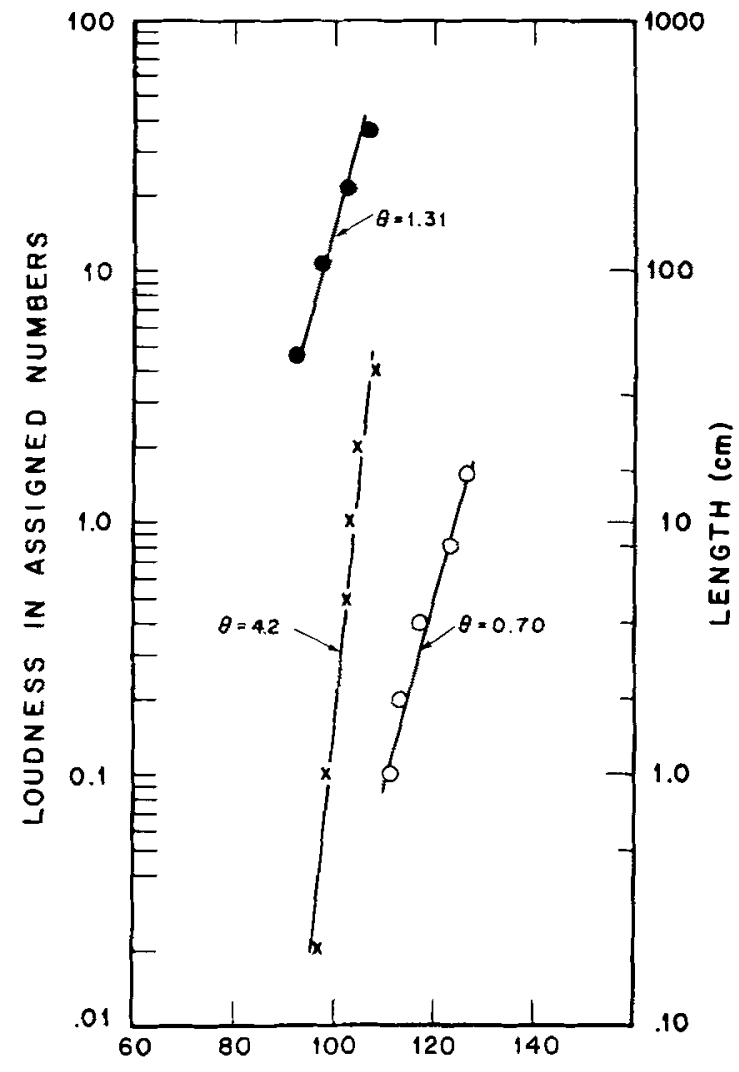

RELATIVE SOUND PRESSURE LEVEL (dB)

Figure 4. Similar to Figure 3, except that data are shown for Observer 3, who had a measured threshold at $1,000 \mathrm{~Hz}$ of $82 \mathrm{~dB}$ SPL.

In conclusion, the results determined by listeners with sensorineural hearing losses provide evidence to support the two hypotheses proposed in this section. An earlier investigation (Thalmann, 1965) showed that transitivity is preserved for group data

Table 5

\begin{tabular}{|c|c|c|c|c|}
\hline \multirow[b]{2}{*}{ bserver } & \multicolumn{4}{|c|}{ Exponent } \\
\hline & $\begin{array}{l}\text { Measured } \\
\text { for Length } \\
\text { re Number }\end{array}$ & Matching & $\begin{array}{l}\text { Predicted } \\
\text { for } \\
\text { Loudness }\end{array}$ & $\begin{array}{c}\text { Measured } \\
\text { for } \\
\text { Loudness* }\end{array}$ \\
\hline 1 & .81 & .83 & .98 & 1.03 \\
\hline 2 & 1.07 & .96 & 1.11 & .97 \\
\hline 3 & 1.77 & .70 & 2.53 & 2.35 \\
\hline
\end{tabular}

* Note-The measured exponents are based on the geometric mean of the individual exponents determined by magnitude estimation and production. determined by listeners with sensorineural impairment, provided that numerical judgments are not used and that the hearing impairment is unilateral. The present results demonstrate that transitivity also extends to individual listeners with bilateral sensorineural losses of long duration. Furthermore, they are consistent with the work by Hellman and Zwislocki (1964), who showed that magnitude estimation and production are valid procedures for measuring the recruitment of loudness produced by an extrinsic masking noise in normal-hearing listeners. Although only three observers participated in the present study, the systematic relationships obtained among the psychophysical functions generated for each observer strongly suggest that the numerical procedures of S. S. Stevens (1958) can also be used to measure directly the slope of the loudness-recruitment function obtained in individual listeners with bilateral sensorineural hearing losses. In accord with S. S. Stevens' expectation $(1959,1969,1975)$, a battery of procedures such as the ones used for these experiments offer a potentially promising approach to the measurement of loudness recruitment in a clinical setting. Additional measurements on a larger population of cochlear-impaired ears are needed to determine the extent of interindividual variability.

\section{REFERENCES}

Barbenza, de, C. M., Bryan, M. E., \& Tempest, W. Individual loudness functions. Journal of Sound and Vibration, 1970, 11, 399-410.

Chocholle, R., \& Greenbaum, H. La sonie de sons purs partiellement masques. Étude comparative par une methode d'égalisation et par la methode des temps de réaction. Journal de Psychologie, 1966,4, 385-414.

Engeland, W., \& Dawson. W. Individual differences in power functions for a 1-week intersession interval. Perception \& Psychophysics, 1974, 15, 349-352.

Hellman, R. P. Effect of spread of excitation on the loudness function at $250 \mathrm{~Hz}$. In H. R. Moskowitz, B. Scharf, \& J. C. Stevens (Eds.), Sensation and measurement. Boston: Reidel, 1974.

Hellman, R. P. Growth of loudness at 1,000 and $3,000 \mathrm{~Hz}$. Journal of the Acoustical Society of America, 1976, 60, 672-679.

Hellman, R. P., \& Zwislocki, J. J. Some factors affecting the estimation of loudness. Journal of the Acoustical Society of America, 1961, 33, 687-694.

Hellman, R. P., \& Zwislock I, J. J. Monaural loudness function at $1,000 \mathrm{cps}$ and interaural summation. Journal of the Acoustical Society of America, 1963, 35, 856-865.

HELLMAN, R. P., \& Zwislocki, J. J. Loudness function of a 1,000 -cps tone in the presence of a masking noise. Journal of the Acoustical Society of America, 1964, 36, 1618-1627.

Hellman, R. P., \& Zwislock I, J. J. Loudness determination at low sound frequencies. Journal of the Acoustical Society of America, 1968, 43, 60-64.

International Organization for Standardization. Expression of the physical and subjective magnitudes of sound [ISO/ R131-1959 (E)]. Geneva: International Organization for Standardization, 1959.

Liliffnthal, M., \& Dawson, W. Inverse cross-modality matching: 
A test of ratio judgment consistency for group and individual data. Perception \& Psychophysics, 1976, 19, 252-260.

LOCHNER. J. P. A., \& BURger. J. F. Form of the loudness function in the presence of masking noise. Journal of the Acoustical Society of America, 1961, 33, 1705-1707.

Logue, A. W. Individual differences in magnitude estimation of loudness. Perception \& Psychophysics, 1976, 19, 279-280.

MARKs, L., \& Bartoshuk, L. Ratio scaling of taste intensity by a matching procedure. Perception \& Psychophysics, 1979, 26, 335-339.

Marks, L., \& Stevens, J. C. Individual brightness functions. Perception \& Psychophysics, 1966, 1, 17-24.

McGill, W. J. The slope of the loudness function: A puzzle. In H. R. Moskowitz, B. Scharf, \& J. C. Stevens (Eds.), Sensation and measurement. Boston: Reidel, 1974.

Miskolczy-Fodor, F. Relation between loudness and duration of tonal pulses. III. Responses in cases of abnormal loudness function. Journal of the Acoustical Society of America, 1960, 32, 486-492.

Sch a RF, B. Partial masking. Acustica, 1964, 14, 16-23.

Schneider, B., \& Lane, H. Ratio scales, category scales, and variability in the production of loudness and softness. Journal of the Acoustical Society of America, 1963, 35, 1953-1961.

Stevens, J. C., \& Guirao, M. Individual loudness functions. Journal of the Acoustical Society of America, 1964, 36, 22102213.

Stevens, S. S. The measurement of loudness. Journal of the Acoustical Society of America, 1955, 27, 815-829.

Stevens, S. S. Concerning the form of the loudness function. Journal of the Acoustical Society of America, 1957, 29, 603-606.

Stevens, S. S. Problems and methods of psychophysics. Psychological Bulletin, 1958, 55, 177-196.

Stevens, S. S. On the validity of the loudness scale. Journal of the Acoustical Society of America, 1959, 31, 995-1003.

Stevens, S. S. On predicting exponents for cross-modality matches. Perception \& Psychophysics, 1969, 6, 251-256.

Stevens, S. S. Issues in psychophysical measurement. Psychological Review, 1971, 78, 426-450.
Stevens, S. S. Psychophysics. New York: Wiley, 1975.

Stevens, S. S., \& Greenbaum, H. Regression effect in psychophysical judgment. Perception \& Psychophysics, 1966, 1, 439-446.

Stevens, S. S., \& Guirao, M. Subjective scaling of length and area and the matching of length to loudness and brightness. Journal of Experimental Psychology, 1963, 66, 177-186.

Stevens, S. S., \& Guirao, M. Loudness functions under inhibition. Perception \& Psychophysics, 1967, 2, 459-465.

Teghtsoonian, M., \& Teghtsoonian, R. How repeatable are Stevens's power law exponents for individual subjects? Perception \& Psychophysics, 1971, 10, 147-149.

Thalmann, R. Cross-modality matching in the study of abnormal loudness functions. Laryngoscope, 1965, 75, 1708-1726.

WALSH, J. K., \& Browman, C. P. Intraindividual consistency on a cross-modality matching task. Perception \& Psychophysics, 1978, 23, 210-214.

Wanschura, R., \& Dawson, W. Regression effect and individual power functions over sessions. Journal of Experimental Psychology, 1974, 102, 806-812.

\section{NOTES}

1. In a recent paper dealing with scaling of taste intensity (Marks \& Bartoshuk, 1979), it is pointed out that the 10\%-25\% discrepancy in exponents obtained for individuals by magnitude estimation and by intramodality matching might be due, at least in part, to the lack of comparable magnitude production data.

2. The selection of points to be included in the least squares analysis was based on the condition that the range of sound pressure levels covered by the combined results of magnitude estimation and production was about equivalent to the range determined by the cross-modality matches.

(Received for publication July 17, 1979; revision accepted August 25, 1980.) 